\title{
Bicornuate uterus and obstetrical complications repeated: what's solution for a better obstetrical prognosis into a developing country of Africa?
}

\author{
Charles Kakou$^{1 *}$, Idrissa Garba ${ }^{2}$, Raoul Kasse ${ }^{1}$, Diomandé Gondo ${ }^{1}$, Koffi Soh ${ }^{1}$, \\ Roland Adjoby ${ }^{1}$, Serge Boni ${ }^{1}$
}

\begin{abstract}
${ }^{1}$ Department of Obstetrics and Gynecology, University Hospital of Cocody, University Felix Houphouet Boigny, Abidjan, Côte d'Ivoire

${ }^{2}$ Department of Medical Imaging and Diagnosis, University hospital of Yopougon, University Felix Houphouet Boigny, Abidjan, Côte d'Ivoire
\end{abstract}

Received: 09 February 2018

Accepted: 07 March 2018

\section{*Correspondence:}

Dr. Charles Kakou,

E-mail: kakoucharles@yahoo.fr

Copyright: ( ) the author(s), publisher and licensee Medip Academy. This is an open-access article distributed under the terms of the Creative Commons Attribution Non-Commercial License, which permits unrestricted non-commercial use, distribution, and reproduction in any medium, provided the original work is properly cited.

\begin{abstract}
Author report one case of bicornuate uterus and pregnancy in a patient who had a preterm delivery in her medical history. The support for the pregnancy was a cerclage of the cervix, bi-monthly prenatal consultation, a systematic work stoppage. The removal of cerclage was conducted at 37 weeks of amenorrhea. Childbirth is done vaginally. We didn't realize restorative surgery of the uterus before pregnancy or after. The aim of our clinical case was to clarify the therapeutic possibilities in an African developing country. Moreover, the formation of an expert team for surgery of uterine malformations should be considered in our work environment.
\end{abstract}

Keywords: Bicornuate uterus, Cervical cerclage, Preterm delivery, Recurrent abortion, Surgery

\section{INTRODUCTION}

Bicornuate uteri appear in $2^{\text {nd }}$ rank of uterine malformations after septate uterus. In the majority of the studies, there are about $55 \%$ of septate uterus, $25-30 \%$ of bicornuate uterus and the other 20 to $15 \% \cdot{ }^{1-3}$ Bicornuate uteri are often discovered in case of obstetrical complications. Indeed, pregnancy associated with a bicornuate uterus is considered to very high risk because of the frequency of obstetrical complications: recurrent abortion, preterm delivery, dystocia, hypotrophic fetus and higher c-section rates. ${ }^{3,4}$

The discovery of bicornuate uterus in a context of obstetrical accident posed a challenge of support whose aim is to carry out the pregnancy to term. Author present a case of bicornuate uterus discovered in this clinical context and our support in according with the literature.

\section{CASE REPORT}

Madam KF, 28 years old, housewife, living in the countryside, had been referred to us for the follow-up of pregnancy about 4 months associated with a bicornuate uterus. Into her medical history, the patient was second gravida primiparous. She benefited to caesarean section at 30 weeks of amenorrhea to the regional hospital center of Daloa (Côte d'Ivoire). A bicornuate uterus had been fortuitous discovery during the caesarean section (Figure 1 and 2). For the occurring pregnancy, we realized a bimonthly prenatal consultation at university hospital of Cocody. Obstetrical ultrasound done at 22 weeks of 
amenorrhea had failed to highlight the uterine malformation; the fetus was morphologically normal and eutrophic. Uterine cervix was normal measured to 47.5 $\mathrm{mm}$ by vaginal ultrasound done at 22 weeks of amenorrhea (Figure 3).

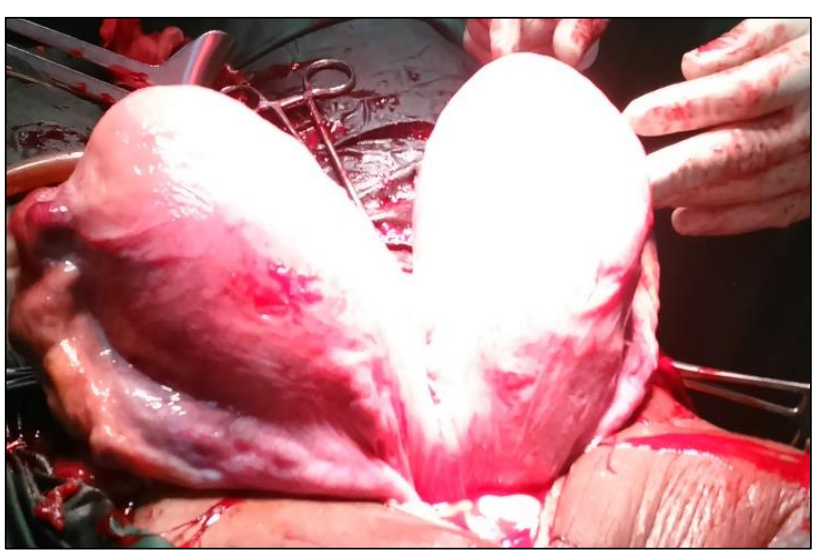

Figure 1: View operating during a c-section; bicornate uterus, view of the posterior.

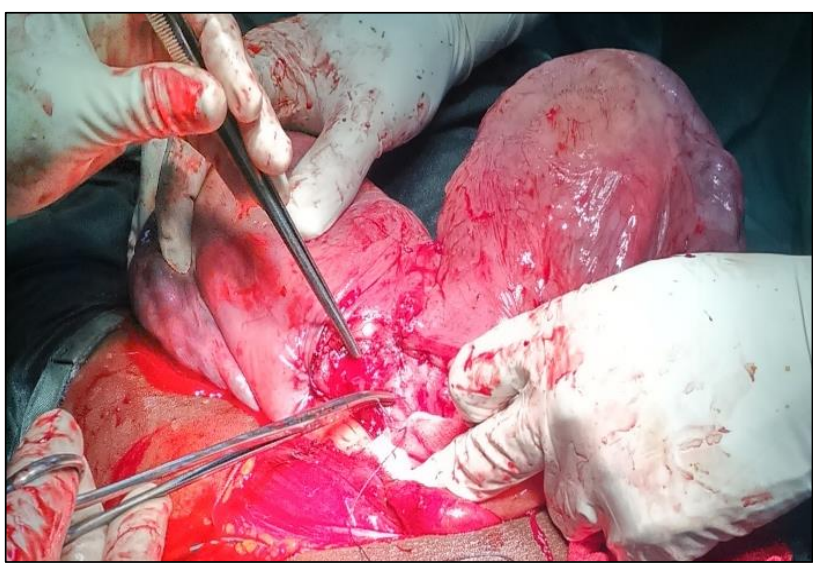

Figure 2: View operating of bicornuate uterus occuring cesarean section: suture of the hysterorraphy after extraction of the fetus.

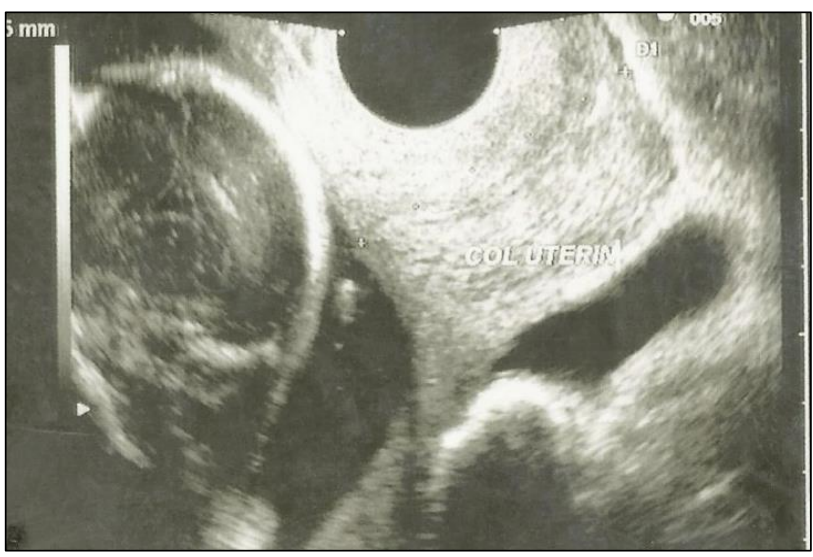

Figure 3: Visualization of uterine cervix measured $47.5 \mathrm{~mm}$ by vaginal ultrasound at 22 weeks of amenorrhea.
However, a prophylactic cerclage was realized at 22 weeks of amenorrhea because of the history. The course of the pregnancy went without incidents followed by the removal of cerclage at 37 weeks of amenorrhea. A vaginal delivery has been done. The baby was in good health of $2800 \mathrm{gm}$.

\section{DISCUSSION}

\section{Epidemiology}

The frequency of uterine malformations is difficult to assess for various reasons. ${ }^{1-6}$ Uterine malformations are often asymptomatic at more than $50 \%$ of the pregnant. ${ }^{3}$ The imaging techniques used for the diagnosis are different depending on the studied series: ultrasound 3D, MRI, sonohystogram 3D. ${ }^{7}$ In addition, the classifications used are different according to the studies; the Musset's classification 1964 is most used in France and Europa. ${ }^{1}$ Overall, a bicornuate uterus, all type confused, is found in 5 to $10 \%$ of women consulting recurrent abortion and $25 \%$ of women who had late miscarriages or preterm delivery repeatedly. ${ }^{3}$ In the case of uterine malformation, there is, according to the authors, 21 to $29 \%$ of preterm deliveries and $25 \%$ of miscarriages early or late. ${ }^{8,9}$ About twin pregnancies, nearly $45 \%$ result in a preterm delivery that's to say that, the association of risk factors twin birth and bicornuate uterus grow up inevitably the risk of preterm delivery. ${ }^{10}$

\section{Diagnosis}

The diagnosis of bicornuate uterus can be done outside of pregnancy, in the context of infertility, in the case of obstetrical accident or fortuitous after a c-section as in the present clinical case. ${ }^{3,11}$ In the majority of cases, medical imaging allows sure diagnosis outside or in early pregnancy. ${ }^{7}$ There are many diagnostic methods, but their availability is a function of the medical development level of country. That can explain the disparity of the frequency data in the literature. For other techniques imaging: sonohystogram coupled with 3D ultrasound or MRI. However, the standard gynecological ultrasound (2D) can bring sufficient elements for the diagnosis. ${ }^{12,13}$ Unfortunately in our medical environment, there is not a widespread availability in pelvic ultrasound, especially in countryside areas; in according with the lack of diagnosis of this type of pathology.

\section{Management}

The problem of the pregnant with a bicornuate uterus is to carry the pregnancy to term. In our case, we did a cervix cerclage because of its antecedent of preterm delivery. The support was supplemented by rest, ultrasound surveillance of uterine cervix and the monitoring of the fetal growth. In the literature, cervix cerclage should be offered only in the case of proven cervical incompetence, what we observe in $25-30 \%$ of cases of uterine malformations. ${ }^{8}$ In a study of a 
population of 98 cas with $75 \%$ of bicornuate uterus, $30 \%$ of the cervix incompetence was diagnosed by hysterosalpingography 98 patients overall. Without surgical correction of uterine anomaly, the rate of preterm delivery and late miscarriages at the pregnant was $50 \%$ without cerclage and $21 \%$ with cerclage, with a significant difference $\mathrm{p}<0.01 .^{8}$ In case of proven cervical incompetence treated by cerclage, the rate of preterm delivery and late miscarriages at the pregnant was $74 \%$ before cerclage and $37 \%$ after; the delivery term rates were $26 \%$ before to $63 \%$ after. The cervix cerclage in case of proven cervical incompetence seems beneficial. ${ }^{14}$ Indeed, in the same series of 98 cases, the preterm delivery rate went from $35.6 \%$ to $4 \%$, rate of delivery term of $64 \%$ to $96 \%$, for all cases of systematic cerclage without proof of cervical incompetence. But more broadly, a cervical cerclage should be systematically carried out in case of occurrence of twins on uterus malformed because of two elements: the uterine surdistension and the already high risk of preterm delivery related to the twins. About surgery of bicornuate uterus, she had been described by Strassman in $1952 .{ }^{15}$ But she had not given real benefits. ${ }^{2}$ Nowadays, only cerclage of the cervix can be widely offered in the case of history of late-term abortion. The intervention of Bret Palmer described in 1959, quoted in the article of Teti, was also abandoned because it didn't give real proven benefits compared to the obstetric consequences considered to be dangerous. ${ }^{16}$ It appears important to focus on a special obstetric care: rest, cerclage, tocolysis, and antenatal corticotherapy. The reconstructive surgery should be reserved for patients whose obstetrical prognosis is extremely unfavorable and whose history reveals several late miscarriages. A Chinese team had published a laparoscopic metroplasty case on bicornuate uterus within a nulliparous, 29 years old, with an obstetric history of repeated miscarriage and suggested a cerclage to the subsequent pregnancy. ${ }^{17}$ For some teams, surgical interventions for bicornuate uterus know a renewed interest. Ayhan et al reported in 1992 on a conventional series of 102 cases of metroplasty according to Strassman followed by uterine cerclage. The results were $75 \%$ of live birth after surgery against $3.7 \%$ live birth before surgery. ${ }^{18}$ Two (2) cases of uterine rupture had been observed as complications. More recently, the endoscopic route is preferentially performed unlike laparotomy, with fewer complications. ${ }^{19}$ In addition, a series of 13 cases of metroplasty laparoscopic technique of Strassmann between 2001 and 2008 had allowed a rate of zero percent live birth before against $80 \%$ after surgery; no cases of uterine rupture or intra-partum complications was observed..$^{20}$

Some authors like Alborzi and coll recommended in addition to surgery, a control by laparoscopy and by hysteroscopy, 3 months post-operative to appreciate the uterine cavity, research and treat a uterine synechiae and pelvic adhesions. ${ }^{19}$ About of a serie of 4 patients, there had 2 cases of uterine synechiae light and no cases of abdominal pelvic adhesions.

\section{CONCLUSION}

There are several treatment options for the management of pregnancy associated to bicornuate uterus responsible of obstetrical accident. These treatments are offered outside the pregnancy. During pregnancy, a cervix cerclage should be systematically proposed by the healthcare's teams in African developing countries.

\section{Funding: No funding sources Conflict of interest: None declared Ethical approval: Not required}

\section{REFERENCES}

1. Philip CA, Rudigoz RC, Huissoud C. Retentissement obstétrical des malformations utérines. EMC Obstétrique. 2016;11(4):1-14.

2. Porcu G, Heckenroth H. Malformations utérines et infertilité. Encyl Med Chir, Elsevier SAS: Paris; 2005:739-A-20.

3. Rossier MC, Bays V, Vial Y, Achtari C. Les malformation utérines: diagnostic, pronostic et prise en charge en 2008. Rev med Suisse. 2008;4:2253-63.

4. Guinard E, Subtil D, Deruelle P. Congenital Müllerian anomalies and delivery: Analysis of 304 cases between 2000 and 2010 at the University Hospital of Lille. Gynécologie Obstétrique et Fertilité. 2014;42(7-8):471-6.

5. Fengbing Liang, Wensheng Hu. Pregnancy complications and obstetric outcomes among women with congenital uterine malformations. Int $\mathbf{J}$ Gynaecol Obstet. 1991;(2):159-60.

6. Raga F, Bauset C, Remohi J. Reproductive impact of congenital Mullerian anomalies. Hum Reprod. 1997;12:2277-81.

7. Deutch TD, Abuhamad AZ. The role of 3dimensional ultrasonography and magnetic resonance imaging in the diagnosis of mullerian duct anomalies: a review of the literature. J Ultrasound Med. 2008;27(3)413-23.

8. Golan A, Langer R, Neuman M, Wexler S, Segev E, David MP. Obstetric outcome in women with congenital uterine malformations. J Reprod Med. 1992;37 (3):233-6.

9. Ludmir J, Samuels P, Brooks S, Mennuti MT. Pregnancy outcome of patients with uncorrected uterine anomalies managed in a high-risk obstetric setting. Obstet Gynecol. 1990;75(6):906-10.

10. Carbonne B, Revaux A. Menace d'accouchement prématuré. In Traité d'obstétrique Elsevier Masson: Paris; 2010:183-189.

11. Lin PC. Reproductive outcome in women with uterine anomalies. J Womens Health. 2004;13(1):339.

12. Lansac J, Lecomte P, Marret H. Malformations de l'appareil génital. In Gynécologie pour le praticien, $7^{\text {th }}$ Éd. Elsevier Masson: Paris; 2007:207-219.

13. Ludwin A, Ludwin I, Banas T, Knafel A, Miedzyblocki M, Basta A. Diagnostic accuracy of 
sonohysterography, hysterosalpingography and diagnostic hysteroscopy in diagnosis of arcuate, septate and bicornuate uterus. J Obstet Gynaecol Res. 2011;37(3):178-86.

14. Golan A, Langer R, Wexler S, Segev E, Niv D, David MP. Cervical cerclage it is role in the pregnant anomalous uterus. Int J Fertil. 1990;35(3):164-70.

15. Strasmann EO. Plastic unification of double uterus: study of 123 collected and five personal cases. Am J Obstet Gynecol. 1952;66:147-50.

16. Teti G, Maffei S, Pippi E, Fioretti P. Reproductive capacity and outcome of pregnancy after metroplasty following the technique of Bret-Palmer partially modified in the pathological symmetric malformations of müllerian ducts. Clin Exp Obstet Gynecol. 1991;18(2):65-70.

17. Sinha R, Mahajan C, Hegde A, Shukla A. Laparoscopic metroplasty for bicornuate uterus. J Minim Invasive Gynecol. 2006;13(1):70-3.

18. Ayhan A, Yücel I, Tuncer ZS, Kişnişçi HA. Reproductive performance after conventional metroplasty: an evaluation of 102 cases. Fertil Steril. 1992;57(6):1194-6.

19. Alborzi S, Asadi N, Zolghadri J, Alborzi S, Alborzi M. Laparoscopic metroplasty in bicornuate and didelphic uteri. Fertil Steril. 2009;92(1):352-5.

20. Rechberger $\mathrm{T}$, Monist $\mathrm{M}$, Bartuzi A. Clinical effectiveness of Strassman operation in the treatment of bicornuate uterus. Ginekologia polska. 2009 Feb;80(2):88-92.

Cite this article as: Kakou C, Garba I, Kasse R, Gondo D, Mian B, Adjoby R, et al. Bicornuate uterus and obstetrical complications repeated: what's solution for a better obstetrical prognosis into a developing country of Africa?. Int J Reprod Contracept Obstet Gynecol 2018;7:1631-4. 